\title{
SYNTHESIS, CHARACTERIZATION AND FILM PREPARATION OF NEW CO-POLYIMIDE BASED ON NEW 3,5-DIAMINO- $N$-(PYRIDIN-4-YLMETHYL)BENZAMIDE, ODA AND 6FDA
}

\author{
ALAIN TUNDIDOR-CAMBA ${ }^{1}$, CESAR SALDIAS ${ }^{2}$, LUIS H. TAGLE ${ }^{l}$, CLAUDIO A. TERRAZA ${ }^{1}$, DEYSMA COLL $L^{1,3}$, \\ GERMÁN PÉREZ ${ }^{1}$, MANUEL AGUILAR-VEGA', ROMINA L. ABARCA AND PABLO A. ORTIZ*1,3
}

\author{
${ }^{1}$ Research Laboratory for Organic Polymers, Faculty of Chemistry, Pontificia Universidad Católica de Chile, Santiago, Chile. \\ ${ }^{2}$ Physical-Chemistry Department, Faculty of Chemistry, Pontificia Universidad Católica de Chile, Santiago, Chile \\ ${ }^{3}$ Núcleo de Química y Bioquímica, Facultad de Estudios Interdisciplinarios, Universidad Mayor, Santiago, Chile. \\ ${ }^{4}$ Unidad de Materiales. Laboratorio de Membranas. Centro de Investigación Científica de Yucatán A.C., Mérida, México \\ ${ }^{5}$ Instituto de Ciencia y Tecnología de los Alimentos, Facultad de Ciencias Agrarias, Universidad Austral, Valdivia, Chile.
}

\section{ABSTRACT}

This work describes mainly the synthesis and characterization of new co-polyimides obtained from the polycondensation of the dianhydride 4,4'-(hexafluoroisopropylidene)diphthalic anhydride (6FDA), 4,4'-oxydianiline (ODA) and the new diamine 3,5-diamino- $N$-(pyridin-4-ylmethyl)benzamide (PyDA). It describes as the different compositions of ODA and PyDA present in the polymers, produce variation on thermal and mechanical properties, which are important characteristics for the development of future nanocomposites derived from these polymers. Both PyDA monomer and polymers were characterized using FT-IR and NMR $\left({ }^{1} \mathrm{H},{ }^{13} \mathrm{C},{ }^{19} \mathrm{~F}\right.$, dept $135^{\circ}$, COSY, HMBC, HMQC) spectroscopy. The inherent viscosity of polymers is between 0.3 to $1.49 \mathrm{dL} / \mathrm{g}$, they are soluble in aprotic polar solvents, such as: DMSO, DMF and DMA. In addition, all co-polymers showed thermal decomposition temperature and glass transition temperatures above $483{ }^{\circ} \mathrm{C}$ and $289^{\circ} \mathrm{C}$, respectively. Mechanical tests under tension of co-polymer films showed Young's modulus between 2.1-3.9 GPa and tensile strength between 35.5 and 120.0 MPa. On the other hand, an increase in crystallinity and hydrophilicity is observed when increasing the amount of pyridinyl groups.

Keywords: aromatic co-polyimides, pendant amide, pyridinyl pendant group.

\section{INTRODUCTION}

Aromatic polyimides and polyamides have been widely used for several decades due to their excellent properties, such as thermal and chemical stability, flame and radiation resistance, mechanical strength and flexibility. ${ }^{1,2}$ While polyimides are they have used as photoresist layers, alignments of liquid crystals, gas separation membranes, electroluminescent devices, polyelectrolytes and fuel cells. ${ }^{3-11}$ Polyamides have been used in personal protection elements, in the military and aerospace industry, high temperature insulating paper and to a great extent for the manufacture of water treatment membranes. ${ }^{12-14}$ However, both are often limited by processing difficulties attributed to the high melting temperature and poor solubility in various organic solvents. Both problems can be explained by the existence of strong interactions due to the formation of intra- and intermolecular charge transfer complexes of the polyimides ${ }^{15,16}$ and to the formation of hydrogen bonds in the polyamides.

To overcome these problems, researchers have worked on designing processable polyimides and polyamides soluble and reducing stiffness or regularity of the chain and minimizing the density of the imide rings or amide groups along the chain. Therefore, it has been proposed to use dianhydrides containing fluorine, such as 4,4'- (hexafluoroisopropylidene)diphthalic anhydride, the incorporation of atoms or groups "hinges", as the oxygen atom in the diamine monomer (for example, 4,4'-oxidianiline) or the use of metaoriented or asymmetric diamines could represent a plausible route. ${ }^{17-22}$

On the other hand, several authors have reported that the incorporation of pyridine and its derivatives into polymer chains increases the thermal stability, electron affinity, electron-transport and offers the possibility of protonation or alkylation site as a way of modifying their properties. The above is due to pyridine is an electron-deficient aromatic heterocycle having a highly localized $\mathrm{sp}^{2}$ lone-pair electrons into nitrogen atom. ${ }^{23-27}$ Moreover, it has been reported that polymers functionalized with nanoparticles containing pyridine groups can be used in technological applications such as absorption and conversion of $\mathrm{CO}_{2}$, homogeneous catalysis, $\mathrm{pH}$ sensors, opto-biodetection and biomedical applications, among others. ${ }^{28-32}$

Considering these backgrounds, in this work we report the synthesis, characterization and preparation of films from a series of soluble aromatic copolyimides derived from 4,4'-(hexafluoroisopropylidene)diphtalic anhydride (6FDA), 4,4'-oxydianiline (ODA) and the new diamine 3,5-diamino- $N$ (pyridin-4-ylmethyl)benzamide (PyDA). These polymers have imide groups which provide both thermal and mechanical stability, partially incorporate a pendant pyridinyl group that will allow functionalization with several nanoparticles in the future, as well as the presence of amide groups that may facilitate water permeability through the membrane. The research explores the effect of the ODA and PyDA proportions used in polymerizations and how the structural composition affects the properties of the synthesized co-polymers.
All this with the aim of establishing the most suitable relationship between the various properties in order to prepare future membranes that are capable of containing nanoparticles.

\section{EXPERIMENTAL}

\subsection{Materials}

Anhydrous acetic anhydride, anhydrous $N, N$-dimethylacetamide (DMA), N,N-dimethylformamide (DMF), dimethylsulfoxide-d (DMSO-d $\mathrm{d}_{6}, \quad N$-methyl-2-pyrrolidinone (NMP), 3,5-dinitrobenzoyl chloride, 4,4'-(hexafluoroisopropylidene)diphthalic anhydride (6FDA), 4,4'-oxydianiline (ODA), $\mathrm{Pd} / \mathrm{C}(10 \% \mathrm{w} / \mathrm{w})$, anhydrous pyridine, pyridin-4ylmethanoamine, tetrahydrofuran (THF) and anhydrous triethylamine (TEA) were obtained from Sigma-Aldrich. Ethanol, ethyl ether and hydrazine $80 \%$ were obtained from Merck KGaA. 4,4'-(hexafluoroisopropylidene)diphthalic anhydride and 4,4'-oxydianiline were purified by sublimation previous to its use.

\subsection{Instrumentation and measurements}

FT-IR spectra ( $\mathrm{KBr}$ pellets) were recorded on a Perkin-Elmer (Fremont CA) 1310 spectrophotometer over the range of 4000-400 $\mathrm{cm}^{-1}$. FT-IR-ATR (ZnSe) were recorded on a Thermo Scientific (Nicolet IS10) spectrophotometer over the range of 4000-400 $\mathrm{cm}^{-1}$. Melting points were obtained on a SMP3 Stuart Scientific melting point apparatus. ${ }^{1} \mathrm{H},{ }^{13} \mathrm{C},{ }^{19} \mathrm{~F}$, dept $135^{\circ}$, COSY, HMBC and HMQC NMR spectra were carried out on a $400 \mathrm{~Hz}$ instrument (Bruker Avance III HD-400) using DMSO- $\mathrm{d}_{6}$ as solvent and TMS as internal standard. Viscosimetry measurements were made in a Desreux-Bischof type dilution viscosimeter at $30^{\circ} \mathrm{C}\left(\mathrm{c}=0.5 \mathrm{gdL}^{-1}\right)$. Glass transition temperature $(\mathrm{Tg})$ values were obtained with a Mettler-Toledo (Greifensee, Switzerland) DSC 821 calorimetric system from the second heating run $\left(10^{\circ} \mathrm{C} \mathrm{min}{ }^{-1}\right.$ under $\mathrm{N}_{2}$ flow). Thermogravimetric analysis were carried out in a Mettler (Switzerland) TA-3000 calorimetric system equipped with a TC-10A processor, and a TG-50 thermobalance with a Mettler MT5 microbalance (temperature range between $25{ }^{\circ} \mathrm{C}$ and $900{ }^{\circ} \mathrm{C}$ at $10{ }^{\circ} \mathrm{C} \mathrm{min}-1$ under constant $\mathrm{N}_{2}$ gas flow). Tensile test was performed under uniaxial tension on a Shimadzu AGS-X universal testing machine with a $100 \mathrm{~N}$ load cell at a crosshead speed of $1 \mathrm{~mm} \mathrm{~min}^{-1}$. The films were cut in strips $0.5 \mathrm{~cm}$ long x $2 \mathrm{~cm}$ wide with thickness between 100 and $60 \mu \mathrm{m}$. The contact angle was determined by the sessile drop method at room temperature using a Dataphysics OCA 20 system. A syringe connected to a Teflon capillary with an internal diameter of approximately $2 \mathrm{~mm}$ was used to introduce the liquids and deposit the respective drop on the films. The surface free energies were calculated by the Owens-Wendt-Kaelble method. Tapping mode AFM images were recorded by using a Bruker atomic force microscope, model Innova. 
2.3 Monomer synthesis and characterization

3,5-Dinitro- $\boldsymbol{N}$-(pyridin-4-ylmethyl)benzamide (PyDN). $15 \mathrm{~mL}(0.148$ mol) of pyridin-4-ylmethanoamine, $100 \mathrm{~mL}$ of THF and $45 \mathrm{~mL}$ of TEA were placed into $500 \mathrm{~mL}$ flask, equipped with a magnetic bar and condenser system. The solution formed was cooled to $0{ }^{\circ} \mathrm{C}$ with an ice water bath and stirred vigorously, then a $34.06 \mathrm{~g}(0.148 \mathrm{~mol})$ solution of 3,5-dinitrobenzoyl chloride in $200 \mathrm{~mL}$ of THF was slowly added. After the addition, the reaction mixture was kept under stirring at $0{ }^{\circ} \mathrm{C}$ for one hour, then it was warmed to room temperature and held therein for an additional hour, and finally refluxed at $100{ }^{\circ} \mathrm{C}$ for another hour to complete the reaction. Upon completion of the reaction, the resulting mixture was poured into $600 \mathrm{~mL}$ of a $\mathrm{NaOH} 5 \%$ aq. solution, resulting in a brown precipitate, which was filtered and dried at 120 ${ }^{\circ} \mathrm{C}$ overnight, finally obtaining $34.2 \mathrm{~g}$ of PyDN, which were subsequently recrystallized from an ethanol:DMF $(9: 1 \mathrm{vol} / \mathrm{vol})$ solvent mixture with a 80 $\%$ yield.

Yield: $85 \%$ (crude). M.p.: 200-201 ${ }^{\circ} \mathrm{C}$. IR (KBr, v, cm $\left.{ }^{-1}\right): 3318(\mathrm{~N}-\mathrm{H})$; 3109, 3078, 3055 (C-H, arom.); 2930, 2872 (C-H, aliph); $1674(\mathrm{C}=\mathrm{N}) ; 1660$ $(\mathrm{C}=\mathrm{O}) ; 1606,1624(\mathrm{C}=\mathrm{C}) ; 1536,1335(\mathrm{~N}-\mathrm{O}) ; 720$ (mono-subst). ${ }^{1} \mathrm{H}$ NMR

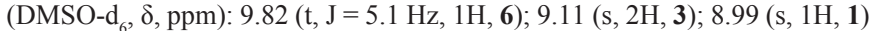
$8.53(\mathrm{~d}, \mathrm{~J}=4.5 \mathrm{~Hz}, 2 \mathrm{H}, \mathbf{1 0}) ; 7.37$ (d, J = 4.6 Hz, 2H, 9); 4.59 (d, J = 5.6 Hz, 2H 7). ${ }^{13} \mathrm{C}$ NMR (DMSO-d $\left., \delta, \mathrm{ppm}\right): 162.5$ (5); 149.6 (10); 148.2 (2); 147.6 (8); 136.5 (4); $127.6(3) ; 122.3(9) ; 121.0(1) ; 42.2$ (7).

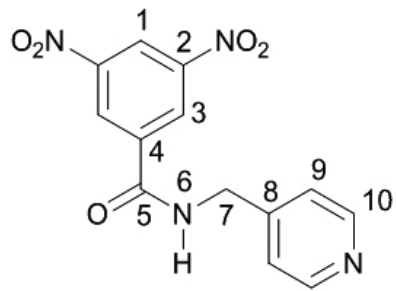

3,5-Diamino- $\boldsymbol{N}$-(pyridin-4-ylmethyl)benzamide (PyDA). $9.9 \mathrm{~g}$ of PyDN, $0.5 \mathrm{~g}$ of $\mathrm{Pd} / \mathrm{C}$ and $200 \mathrm{~mL}$ of ethanol were placed into $250 \mathrm{~mL}$ flask equipped with a magnetic bar and a condenser system. The reaction mixture was vigorously stirred and heated up $70{ }^{\circ} \mathrm{C}$. When the mixture reached that temperature $10 \mathrm{~mL}$ ofhydrazine was added dropwise. After the addition, the mixture was refluxed at $100{ }^{\circ} \mathrm{C}$ and held there to for up to three hours. The resultant mixture was rapidly filtered over celite and the solution obtained is concentrated to dryness. Subsequently, $200 \mathrm{~mL}$ of ethyl ether were added to the obtained solid. This new mixture was stirred for a two hours and filtered, obtaining $7.53 \mathrm{~g}$ of PyDA in $95 \%$ yield. Finally, PyDA was purified by sublimation at $180{ }^{\circ} \mathrm{C}$ with an $80 \%$ efficiency.

Yield: $95 \%$ (crude). Mp: $167-169^{\circ} \mathrm{C}$. IR $\left(\mathrm{KBr}, \mathrm{v}, \mathrm{cm}^{-1}\right): 3412,3339,3201$ (N-H); 3078, 3029 (C-H, arom.); 2988, 2966, 2918 (C-H, aliph); 1632 (C=O); 1592, $1535(\mathrm{C}=\mathrm{C}) ; 709$ (mono-subst). ${ }^{1} \mathrm{H}$ NMR (DMSO-d $\left., \delta, \mathrm{ppm}\right): 8.67(\mathrm{t}$, $\mathrm{J}=5.7 \mathrm{~Hz}, 1 \mathrm{H}, \mathbf{6}) ; 8.49(\mathrm{~d}, \mathrm{~J}=4.8 \mathrm{~Hz}, 2 \mathrm{H}, \mathbf{1 0}) ; 7.26(\mathrm{~d}, \mathrm{~J}=4.8 \mathrm{~Hz}, 2 \mathrm{H}, \mathbf{9})$; 6.30 (s, 2H, 3); 5.99 (s, 1H, 1); 4.89 (s, 4H, 11); 4.41 (d, J = 5.9 Hz, 2H, 7). ${ }^{13} \mathrm{C}$ NMR (DMSO-d,$\delta$, ppm): 168.2 (5); 149.5 (10); 149.2 (2); 149.1 (8); 136.0 (4); 122.1 (9); 102.3 (1); 102.1 (3); 41.6 (7).

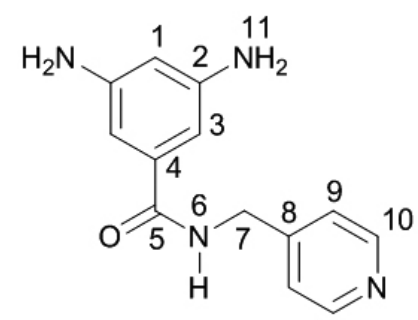

2.4 Polymers synthesis and spectroscopy characterization

$10 \mathrm{mmol}$ of the diamines and $10 \mathrm{~mL}$ of DMA were placed into a 50 $\mathrm{mL}$ three-necked flask equipped with a mechanical stirrer. The mixture was vigorously stirred under a nitrogen atmosphere until complete dissolution of the diamines. Thereafter, the solution was cooled to $0{ }^{\circ} \mathrm{C}$ in a water-ice bath, then $10 \mathrm{mmol}$ of $6 \mathrm{FDA}$ and $10 \mathrm{~mL}$ of DMA were added. This reaction mixture was stirred until completing the dissolution of 6FDA. Then, the bath ice-bath was then removed and the reaction mixture was allowed to stand overnight ( $\sim 12$ hours) at room temperature. Subsequently, to this solution was added 50 mmol of pyridine and a determined volume of anhydrous acetic anhydride. The new solution was kept under stirring for 2 hours at room temperature. Later, the solution was heated to $60{ }^{\circ} \mathrm{C}$ for one hour and after completion of the reaction the solution was slowly poured into $600 \mathrm{~mL}$ of distilled water. The formed solid was filtered and dried at $150{ }^{\circ} \mathrm{C}$ overnight. To purify the polymer, this was dissolved in DMF and subsequently re-precipitated with ethanol. To be extracted later with acetone in a soxhlet.

The five synthesized polymers are referred to as $\mathbf{P O 6}-\mathbf{Z} / \mathbf{X}$, where $\mathbf{P}$ corresponds to the 3,5-diamino- $N$-(pyridin-4-ylmethyl)benzamide (PyDA), $\mathbf{O}$ to $4,4^{\prime}$-oxydianiline (ODA) and 6 to 4,4'-(hexafluoroisopropylidene)diphthalic anhydride (6FDA). Z/X label corresponds to the feed PyDA/ODA monomers molar ratio considering that $10 \mathrm{mmol}$ of 6 FDA monomer were used in each polymerization.
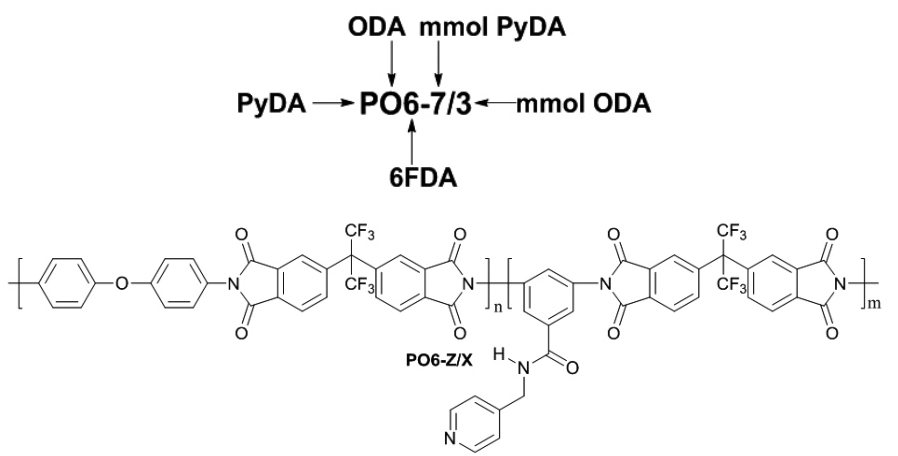

PO6-10/0. FT-IR-ATR (ZnSe, v, $\left.\mathrm{cm}^{-1}\right): 3080,3060,3015$ (C-H, arom); 2980, 2905 (C-H, aliph); 1783, $1718(\mathrm{C}=\mathrm{O}) ; 1590,1542,1498(\mathrm{C}=\mathrm{C}) ; 1244$ $(\mathrm{C}-\mathrm{N}), 740,719$ (p-subst). ${ }^{1} \mathrm{H}$ NMR (DMSO- $\left.d_{6}, \delta, \mathrm{ppm}\right): 9.33$ (s, 1H, 6); 8.50 (s, 2H, 10); 8.23 (d, 2H, 17); 8.14 (s, 2H, 3); 8.01 (d, 2H, 18); 7.82 (s, 3H, 1,14); 7.34 (s, 2H, 9); 4.54 (s, 2H, 7). ${ }^{13} \mathrm{C}$ NMR (DMSO- $d, \delta$, ppm): 165.9 (20); 165.7 (19); 164.8 (5); 149.4 (10); 148.4 (8); 137.5 (13); 136.0 (18), $135.6(\mathbf{2}) ; 133.0$ (16); 132.6 (4); 132.4 (15); 128.9 (1); 126.3 (3); 124.6 (17); 123.8 (14); 122.1 (9); 121.9 (11); 64.7 (t, 12); 42.0 (7). ${ }^{19} \mathrm{~F}$ NMR (DMSO- $d, \delta$, ppm): -62.9

PO6-7/3. FT-IR-ATR (ZnSe, v, cm $\left.{ }^{-1}\right): 3065,3041,3015$ (C-H, arom); 2986, 2966, 2905 (C-H, aliph); 1784, $1717(\mathrm{C}=\mathrm{O}) ; 1629,1600,1539,1498$ $(\mathrm{C}=\mathrm{C}) ; 1349$ (C-N), 1240 (C-O); 740, 719 (p-subst). ${ }^{1} \mathrm{H}$ NMR (DMSO-d ${ }_{6}, \delta$, ppm): 9.33 (s, 7H, 6); 8.51 (s, 14H, 10); $8.21(\mathrm{~m}, 20 \mathrm{H}, 17) ; 8.14(\mathrm{~s}, 14 \mathrm{H}, 3)$ $7.99(\mathrm{~m}, 20 \mathrm{H}, \mathbf{1 8}) ; 7.80(\mathrm{~m}, 27 \mathrm{H}, \mathbf{1 , 1 4}) ; 7.51(\mathrm{~d}, 12 \mathrm{H}, 22) ; 7.34(\mathrm{~s}, 14 \mathrm{H}, \mathbf{9}) ; 7.26$ $(\mathrm{d}, 12 \mathrm{H}, 22) ; 4.54(\mathrm{~d}, 14 \mathrm{H}, 7) .{ }^{13} \mathrm{C}$ NMR (DMSO- $\left.d_{6}, \delta, \mathrm{ppm}\right): 166.2,166.1(\mathbf{2 0})$ 165.9, 165.7 (19); 164.9 (5); 156.1 (24); 149.4 (10); 148.6 (8); 137.5, 137.4 (13); 136.0, 135.9 (18), 136.0 (2); 133.1, 133.0 (16); 132.6 (4); 132.6, 132.4 (15); 129.4 (22); 129.0 (1); 127.2 (21); 126.3 (3); 124.6, 124.4 (17); 123.8 123.6 (14); 122.3 (9); 122.0 (11); 119.2 (23); 64.7 (t, 12); 42.0 (7). ${ }^{19} \mathrm{~F}$ NMR (DMSO- $\left.d_{6}, \delta, \mathrm{ppm}\right):-62.9$

PO6-5/5. FT-IR-ATR (ZnSe, v, $\left.\mathrm{cm}^{-1}\right): 3072,3039$ (C-H, arom); 2970, $2909(\mathrm{C}-\mathrm{H}$, aliph); 1786, $1719(\mathrm{C}=\mathrm{O}) ; 1622,1593,1539,1498,1452(\mathrm{C}=\mathrm{C})$ 1355 (C-N), 1234 (C-O); 743, 714 (p-subst). ${ }^{1} \mathrm{H}$ NMR (DMSO- $\left.d_{6}, \delta, p p m\right)$ : $9.32(\mathrm{~s}, 1 \mathrm{H}, \mathbf{6}) ; 8.50(\mathrm{~s}, 2 \mathrm{H}, \mathbf{1 0}) ; 8.21(\mathrm{~m}, 4 \mathrm{H}, \mathbf{1 7}) ; 8.13(\mathrm{~s}, 2 \mathrm{H}, \mathbf{3}) ; 7.98(\mathrm{~m}$ $4 \mathrm{H}, \mathbf{1 8}) ; 7.79$ (s, 5H, 1,14); 7.51 (m, 4H, 22); 7.34 (s, 2H, 9); 7.25 (d, 4H, 23); 4.54 (s, 2H, 7). ${ }^{13} \mathrm{C}$ NMR (DMSO- $\left.d, \delta, \mathrm{ppm}\right): 166.2,165.9(\mathbf{2 0}) ; 166.1,165.7$ (19); 164.8 (5); 156.1 (24); 149.3 (10); 148.5 (8); 137.5, 137.3 (13); 135.8 (18), 135.6 (2); 133.0, 132.9 (16); 132.6 (4); 132.6, 132.4 (15); 129.3 (22); 129.0 (1); 127.2 (21), 126.3 (3); 124.5, 124.4 (17); 123.8, 123.6 (14); 122.3 (9); 121.9 (11); 119.1 (23); $64.6(\mathrm{t}, 12) ; 42.0(7) .{ }^{19} \mathrm{~F}$ NMR (DMSO- $d, \delta$, ppm): -62.9.

PO6-3/7. FT-IR-ATR (ZnSe, $\left.v, \mathrm{~cm}^{-1}\right): 3068,3039$ (C-H, arom); 2934, $2912(\mathrm{C}-\mathrm{H}$, aliph); 1780, $1716(\mathrm{C}=\mathrm{O}) ; 1624,1593,1500,1455(\mathrm{C}=\mathrm{C}) ; 1375$ (C-N), 1234 (C-O); 744, 714 (p-subst). ${ }^{1} \mathrm{H}$ NMR (DMSO- $\left.d, \delta, \mathrm{ppm}\right): 9.32$ (s, 1H, 6); 8.51 (s, 2H, 10); $8.20(\mathrm{~m}, 4 \mathrm{H}, \mathbf{1 7}) ; 8.13$ (s, 2H, 3); 7.97 (m, 4H, 18); 7.77 (s, 5H, 1,14); 7.51 (m, 4H, 22); 7.34 (s, 2H, 9); 7.25 (d, 4H, 23); 4.54 (s $2 \mathrm{H}, 7) .{ }^{13} \mathrm{C}$ NMR (DMSO- $d, \delta, \mathrm{ppm}$ ): 166.2, 165.9 (20); 166.1, 165.7 (19); 164.8 (5); 156.1 (24); 149.3 (10); 148.6 (8); 137.5, 137.3 (13); 135.8 (18), 135.6 (2); 133.1, 133.0 (16); 132.7 (4); 132.6, 132.4 (15); 129.3 (22); 129.0 (1); 127.2 (21), $126.3(\mathbf{3}) ; 124.5,124.4$ (17); $123.8,123.6(\mathbf{1 4}) ; 122.3$ (9); 122.0 (11); $119.1(\mathbf{2 3}) ; 64.6(\mathrm{t}, \mathbf{1 2}) ; 42.0(7) .{ }^{19} \mathrm{~F}$ NMR (DMSO- $\left.d_{6}, \delta, \mathrm{ppm}\right):-62.9$.

PO6-0/10. FT-IR-ATR (ZnSe, v, $\left.\mathrm{cm}^{-1}\right): 3061,3039,3015(\mathrm{C}-\mathrm{H}$, arom); 2977, 2962 (C-H, aliph); 1784, $1714(\mathrm{C}=\mathrm{O}) ; 1623,1598,1541,1436(\mathrm{C}=\mathrm{C})$ 1369 (C-N), 1229 (C-O); 744, 711 ( $p$-subst). ${ }^{1} \mathrm{H}$ NMR (DMSO- $d_{6}, \delta$, ppm): 8.9 $(\mathrm{d}, J=7.9 \mathrm{~Hz}, 2 \mathrm{H}, 17) ; 7.98$ (d, $J=7.4 \mathrm{~Hz}, 2 \mathrm{H}, 18) ; 7.77$ (s, 2H, 14); 7.50 (d, $J$ $=8.2 \mathrm{~Hz}, 4 \mathrm{H}, 22) ; 7.25(\mathrm{~d}, J=8.2 \mathrm{~Hz}, 4 \mathrm{H}, 23) \cdot{ }^{13} \mathrm{C}$ NMR (DMSO- $\left.d, \delta, \mathrm{ppm}\right)$ : 166.2 (20); 166.1 (19); 164.8 (5); 156.1 (24); 137.3 (13); 135.8 (18), 133.0 
(16); 132.6 (15); 129.3 (22); 127.1 (21); 124.4 (17); 123.6 (14); 121.9 (11); 119.1 (23); $64.6(\mathrm{t}, \mathbf{1 2}) .{ }^{19} \mathrm{~F}$ NMR (DMSO- $\left.d_{6}, \delta, \mathrm{ppm}\right):-62.8$.

\subsection{Films preparation}

Films were prepared from a solution with $400 \mathrm{mg}$ of co-polymer in $10 \mathrm{~mL}$ of DMF. The solution was filtered through on glass fiber of $3.1 \mu \mathrm{m}$ porosity and poured into a $5.5 \mathrm{~cm}$ in diameter glass ring, which, in turn, was on a $20 \mathrm{x}$ $20 \mathrm{~cm}$ glass square. This system was put on a heating plate and heated to 40 ${ }^{\circ} \mathrm{C}$ for 12 hours. Subsequently, the formed film was removed and placed on a stainless-steel mesh and dried for 24 hours at $200{ }^{\circ} \mathrm{C}$. Resulting films have thickness between 35.8 to $85.9 \mu \mathrm{m}$.

\section{RESULTS AND DISCUSSION}

3.1 Monomer synthesis

The synthesis of the PyDA monomer was carried out using the procedure described in scheme 1. Starting from 3,5-dinitrobenzoyl chloride and pyridin4-ylmethanoamine was possible to obtain the dinitro PyDN intermediate with an $85 \%$ yield. The reaction was carried out in THF, in order to dissolve precursors and favour the PyDN precipitation. In this case, TEA was used as a base to neutralize the protons released during the substitution reaction in the acyl, those that considerably reduce the yield of the reaction. Once finished the reaction, it was poured into $5 \% \mathrm{NaOH}$ aq. solution to allow total PyDN precipitation. Note that once the synthesis of these types of compounds has been completed, they are usually poured into acidic water, which for this case is unfeasible due to the presence of the pyridinyl group, which would be protonated by making PyDN soluble in the acid solution.
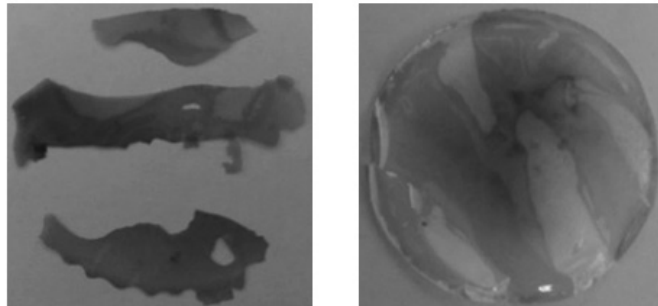

PO6-10/0 (57.5 $\mu \mathrm{m})$

PO6-7/3 (85.9 $\mu \mathrm{m})$

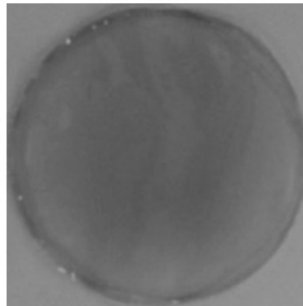

PO6-5/5 (65.5 $\mu \mathrm{m})$
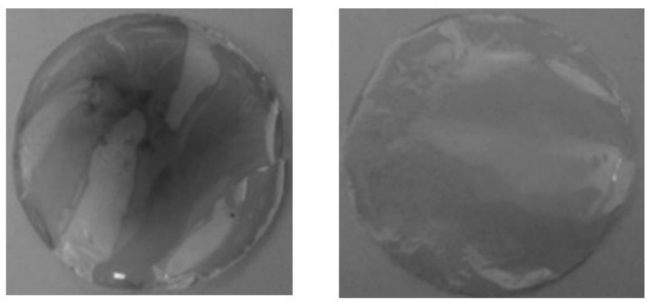

PO6-3/7 $(62.9 \mu \mathrm{m}) \quad$ PO6-0/10 $(35.8 \mu \mathrm{m})$

Figure 1. Digital camera images of polyimides films.

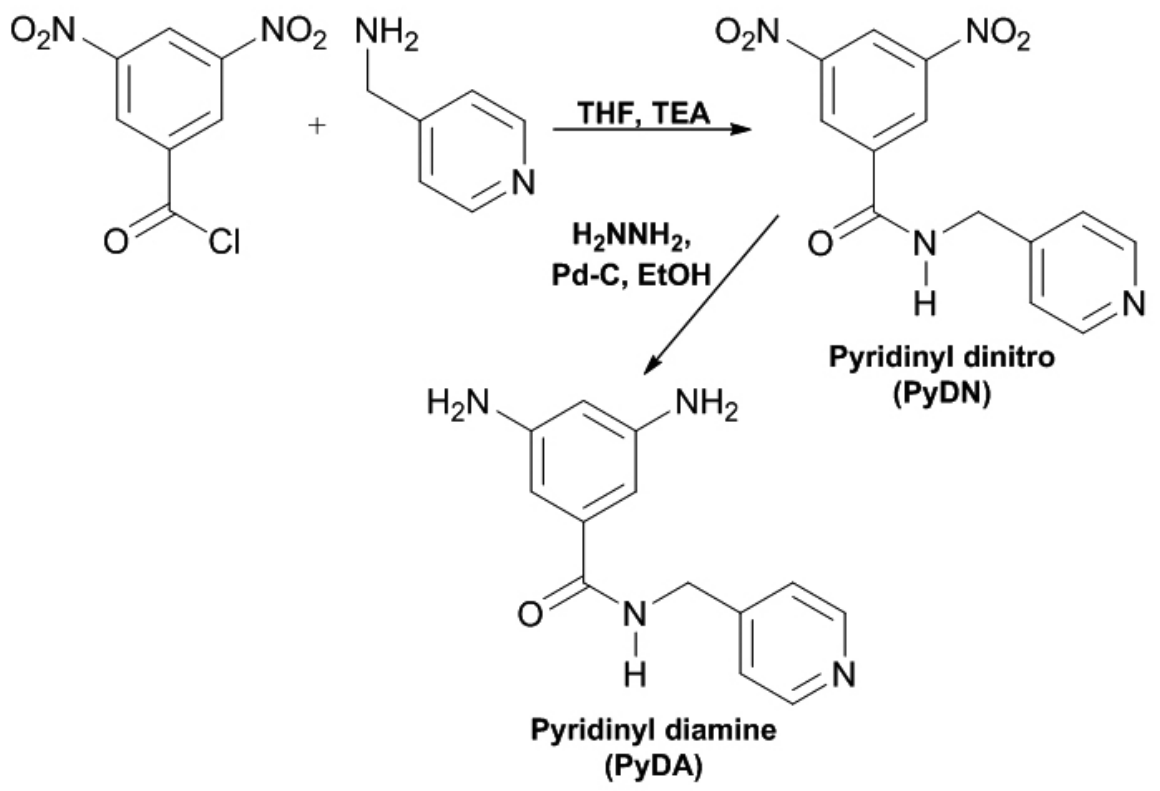

Scheme 1. Synthesis of 3,5-diamino- $N$-(pyridin-4-ylmethyl)benzamide (PyDA). 
The structure of PyDN was verified by means FT-IR, ${ }^{1} \mathrm{H}$ and ${ }^{13} \mathrm{C}$ NMR spectroscopy, and the $135^{\circ} \mathrm{dept}$, COSY, HMBC, HMQC techniques. The first one reveals the existence of the most important groups, such as: the amide group, by the bands in $1675(\mathrm{C}=\mathrm{O})$ and $3329 \mathrm{~cm}^{-1}(\mathrm{~N}-\mathrm{H})$, the nitro groups with signals at 1540 and $1335 \mathrm{~cm}^{-1}$, and the presence of the aromatics $\mathrm{C}=\mathrm{C}$ in 1606 $\mathrm{cm}^{-1}$ and $1624 \mathrm{~cm}^{-1}$. On the other hand, the NMR is clear in determining the nature of PyDN. The figure 2a shows the ${ }^{1} \mathrm{H}$ NMR spectrum where is possible to observe signals for all hydrogen expected for this dinitro derivative with their respective assignments. Within these signals, those observed for 6 and 7 stand out, which show a coupling due to a lower exchange of the amide hydrogen with the solvent.

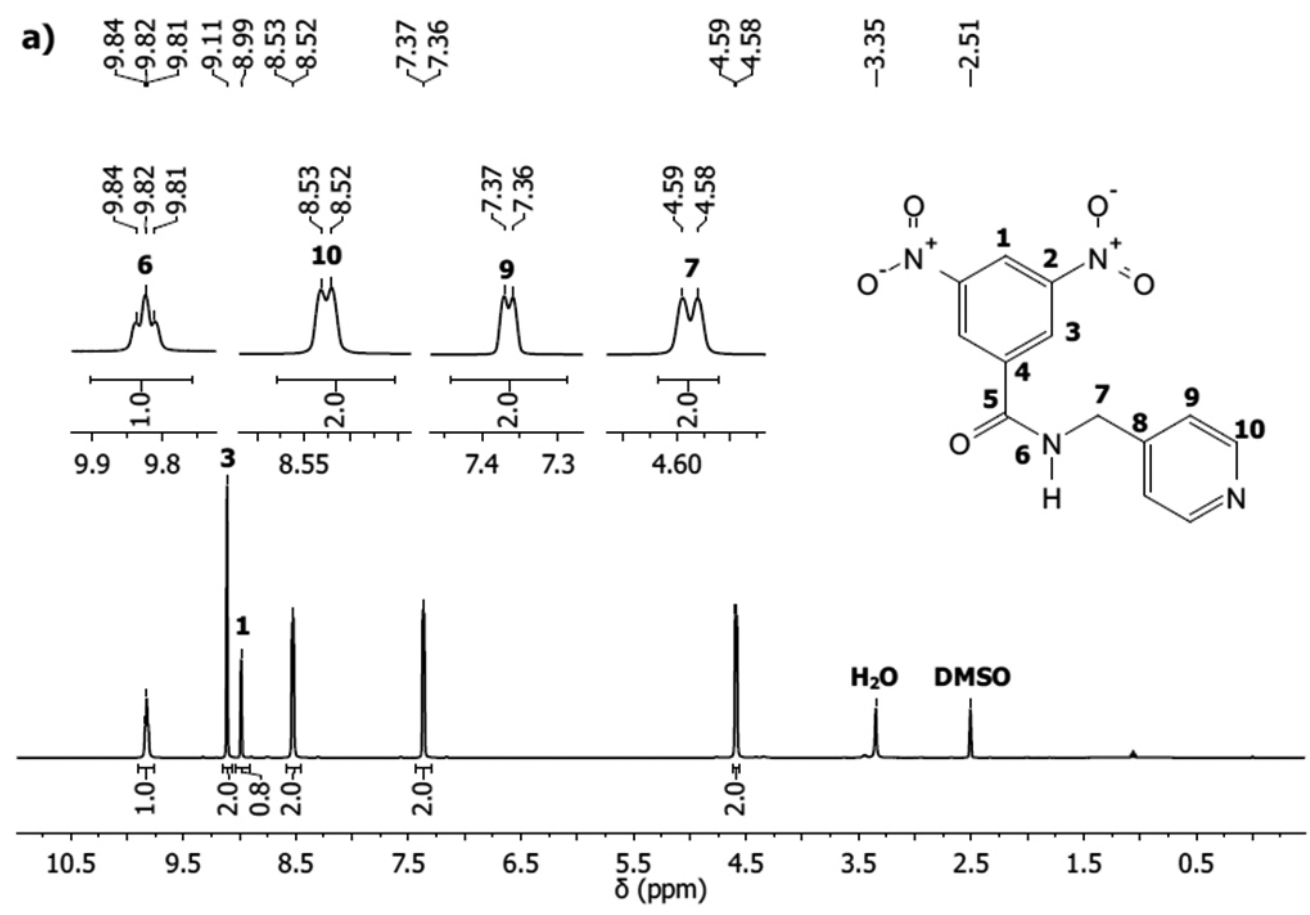

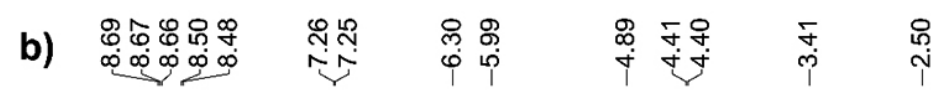

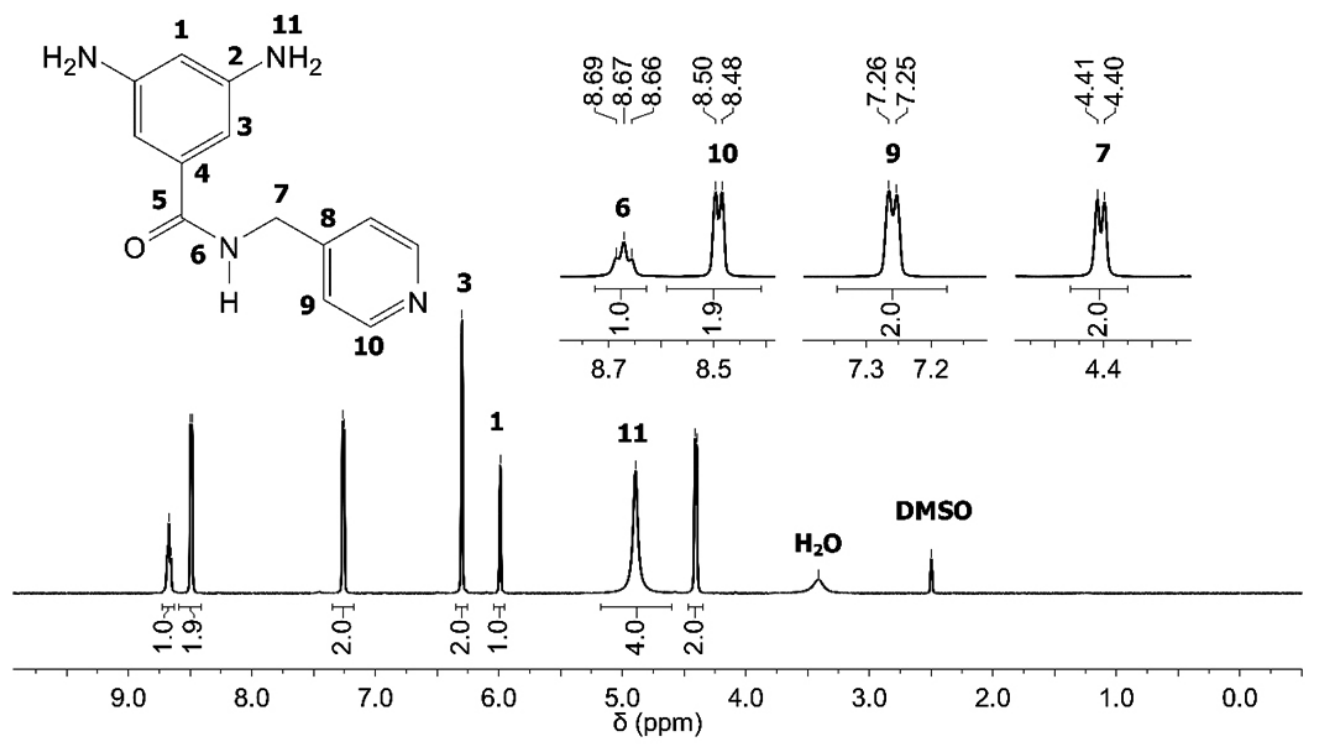

Figure 2. ${ }^{1} \mathrm{H}$ NMR spectrum (400 MHz, DMSO- $d_{6}$ ) a) 3,5-dinitro- $N$-(pyridin-4-ylmethyl)benzamide and b) 3,5-diamino- $N$-(pyridin-4-ylmethyl)benzamide. 
In the second stage to produce PyDA, hydrazine and $\mathrm{Pd} / \mathrm{C}$ were used to selectively reduce the amino groups in ethanol as solvent. Unlike classical technique for this type diamine synthesis, once the remaining $\mathrm{Pd} / \mathrm{C}$ was filtered, the solution was concentrated to dryness. Diethylether $200 \mathrm{~mL}$ were poured over the diamine to eliminate the remains of ethanol present. This was done since the diamine is soluble in water. On the other hand, recrystallization or sublimation are generally used in the purification of this type of monomers. In this case, sublimation was used, because in the recrystallization, which can be done in water or ethanol, it generates the coloration of the obtained crystals.

Obtaining the PyDA using IR and NMR spectroscopy was also corroborated. From IR analysis, the appearance of the N-H signals $\left(3412 \mathrm{~cm}^{-1}\right.$ y $3339 \mathrm{~cm}^{-1}$ ) of the formed amines and the disappearance of the signals at 1335 $\mathrm{cm}^{-1}$ and at $1536 \mathrm{~cm}^{-1}$ of the nitro groups of PyDN were observed. In NMR analysis, the identification and assignment of the different nuclei was carried out using all the mentioned techniques. In the figure $2 \mathrm{~b}$, spectrum shows nitro groups conversion to amino generates a displacement of the signals of the ring hydrogens towards high magnetic fields. This fact was due to the shielding generated by the amino groups, an effect that can also be seen on the hydrogen of the amide group. In addition, Figure 3 shows the NMR spectrum of ${ }^{13} \mathrm{C}$ and HMQC of PyDA which would corroborate the performed assignation.

Figure 3 a:
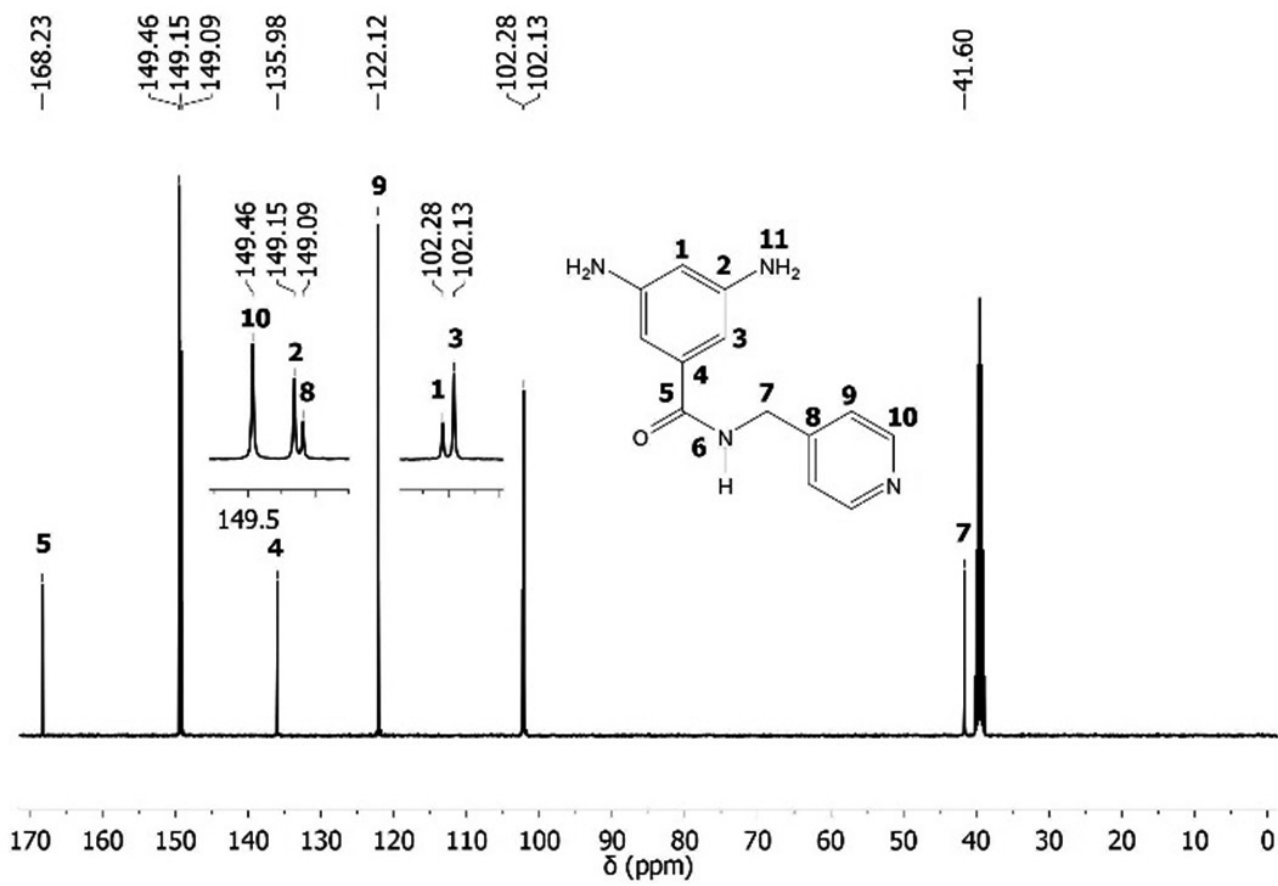

Figure 3 b:

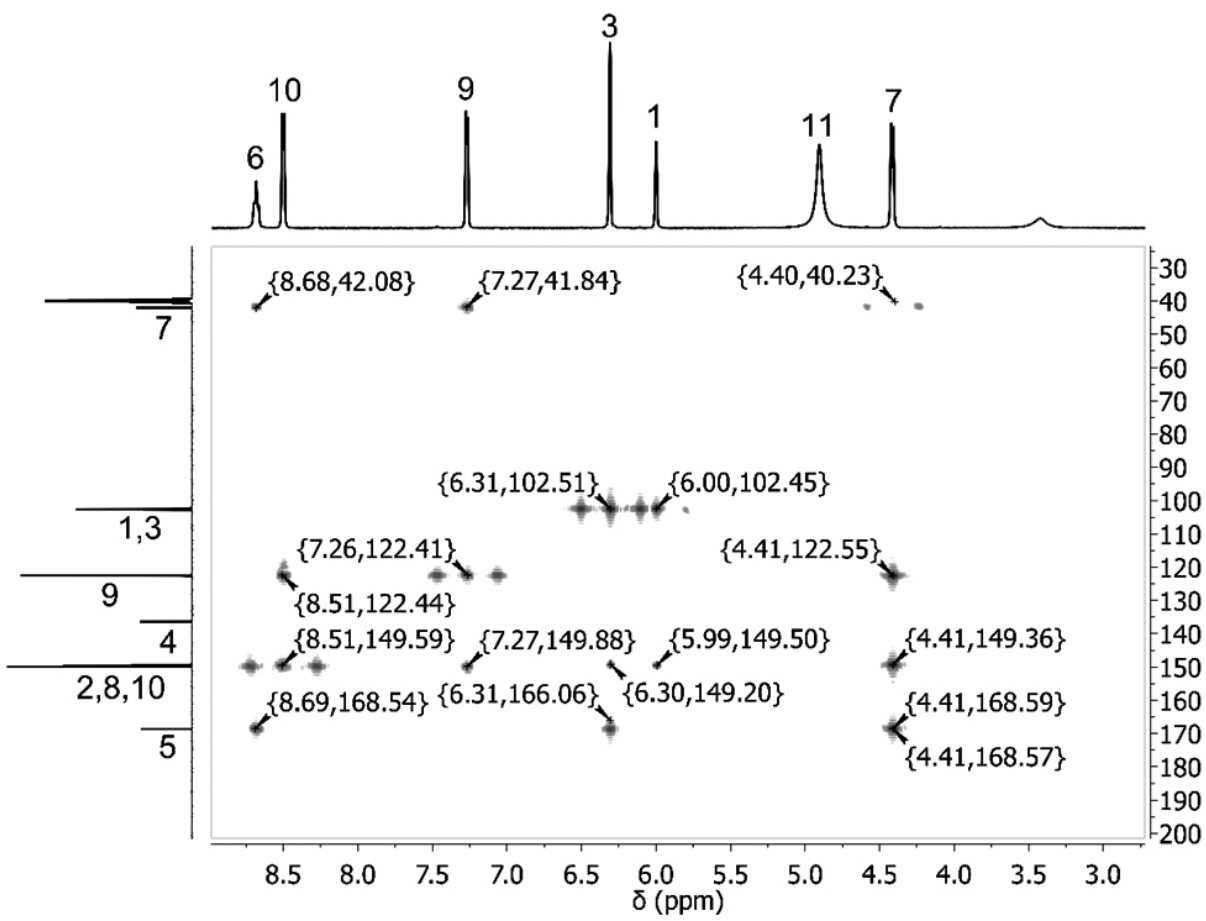

Figure 3. ${ }^{13} \mathrm{C}$ NMR and HMQC spectrum (400 MHz, DMSO- $d_{6}$ ) of 3,5-diamino- $N$-(pyridin-4-ylmethyl) benzamide 


\subsection{Polymers synthesis}

The synthesis of the co-polymers was carried out in two stages as described in scheme 2. The first stage produces the opening of the anhydrous groups by action of the amino groups of both diamines to obtain the co-polyamic acid In the second stage, using acetic anhydride and pyridine the cyclization and formation of the imide groups was generated. The first stage was carried out for around 12 hours to favour the nucleophilic attack of PyDA, which shows a lower reactivity due to the deactivating effect of the amide group and the second stage is performed in a usual way for this type of polymerization. The co-polyimides were precipitated in water and dried at $150{ }^{\circ} \mathrm{C}$ overnight to remove the DMA, giving a $99 \%$ yield in each reaction.

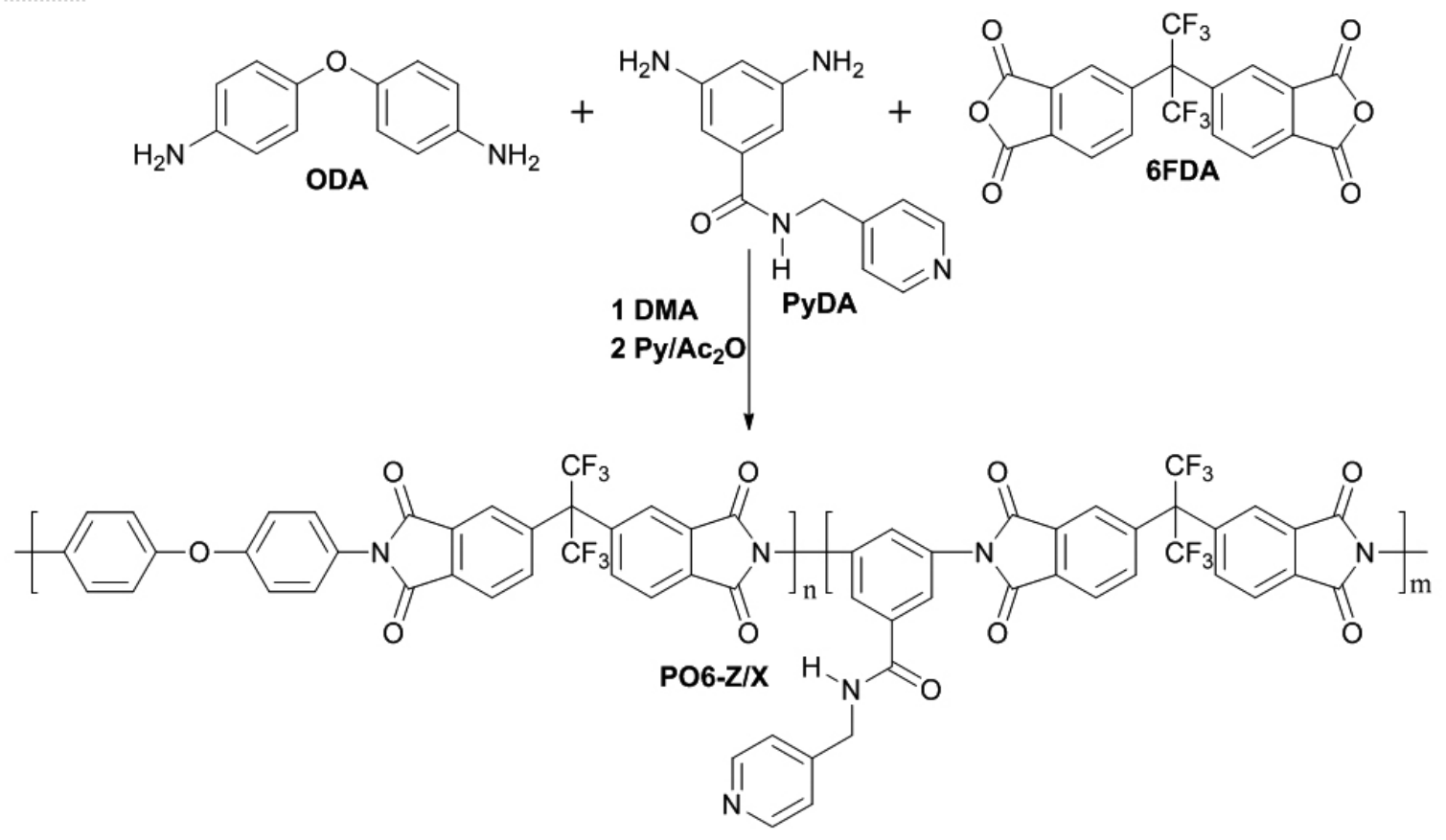

Scheme 2. Synthesis of co-polyimide (PO6-Z/X).

To remove traces of occluded monomer, the polymers were purified by re-precipitation from a polymer solution in DMF with ethanol and subsequent extraction with acetone.

The structural determination of the repetitive unit of the co-polymers was carried out using the spectroscopic techniques previously described for the monomers, in which the clear presence of the desired polymers was observed FT-IR spectroscopy allows to distinguish the presence of the imide groups formed during the polymerization with the presence of two bands at 1714 and $1784 \mathrm{~cm}^{-1}$, which indicate the presence of amidic $\mathrm{C}=\mathrm{O}$. The rest of the bands agree with those presented in the monomers, indicating that the structure of them did not undergo modifications during the polymerization process.

On the other hand, the NMR spectroscopies account for the expected nuclei for the polymers allowing the assignment of each of them within the chains formed. In figure 4 , an example of such assignments in the ${ }^{1} \mathrm{H}$ and ${ }^{13} \mathrm{C}$ NMR spectrum of PO6-5/5 can be seen, which were corroborated using the dept $135^{\circ}, \mathrm{COSY}, \mathrm{HMBC}$ and HMQC spectra. This was also done considering that PO6-10/0 and PO6-0/10 only present the monomers diamine PyDA or ODA; respectively, which allows to accurately distinguish the presence of each of the fragments contributed by each monomer in the three co-polymers.

To corroborate that the ODA/PyDA ratio used was transferred to the copolymers, the ${ }^{1} \mathrm{H}$ NMR spectrum was recovered after the purification process, which eliminates the smaller chains. For this, the methylenic hydrogen $(\mathrm{H} 7)$ are used as a reference, because it is only in fragment derived from PyDA and maintains the expected relationship with each of the hydrogens, both in its fragment and that coming from the monomers ODA and 6FDA.

On the other hand, in the ${ }^{13} \mathrm{C}$ spectrum the signals belonging to the carbons that are part of the dianhydride moiety have a different magnetic environment, depending on the fragment of the diamine monomer that is at their side, causing them to present two signals for each one of these nuclei.
3.3 Viscosity and solubility

Table 1 shows the values of inherent viscosity and solubility tests for each polymer synthesized, together with the values obtained by Bong et al. for PO6$0 / 10$ (polyimide derived from 6FDA and ODA) ${ }^{33}$ which has a viscosity similar to that we prepared. These values describe how increasing the amount of ODA in the polymer chain increases the viscosity, which results in an increase in molecular weight. As is known, the viscosity of a polymer, among other factors, depends directly on the size of the chain and based on this fact, it is expected that polymers having a higher ODA content have longer chains. This tendency was expected due to the greater reactivity of the ODA monomer compared to the PyDA, an effect that favours the growth of the polyimide chains.

The solubility tests carried out at room temperature and under heating show that the polymers are soluble in polar aprotic solvents such as DMSO or NMP among others, while they are insoluble in protic polar solvents such as methanol and ethanol. A special behaviour is present, in the case of PO6$10 / 0$, which shows swelling due to the high content of pyridinyl groups in protic polar solvents. This same effect is seen with solvents such as acetone and chloroform, which show a tendency to swell depending on pyridinyl group content. In the case of acetone, the presence of this moiety favours the swelling and in the case of chloroform it decreases. It is also observed that a simila distribution of fragments of both diamines (PO6-5/5) show solubility in THF and that the polymers are insoluble in apolar solvent as $\mathrm{Et}_{2} \mathrm{O}$. 


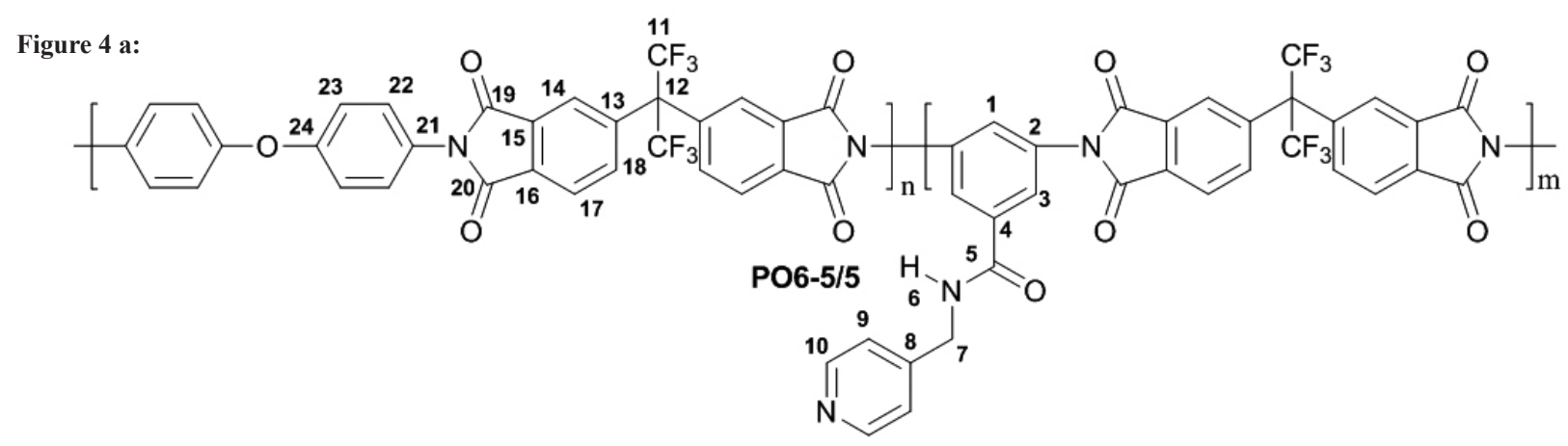

Figure 4 b:

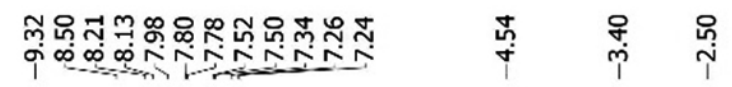
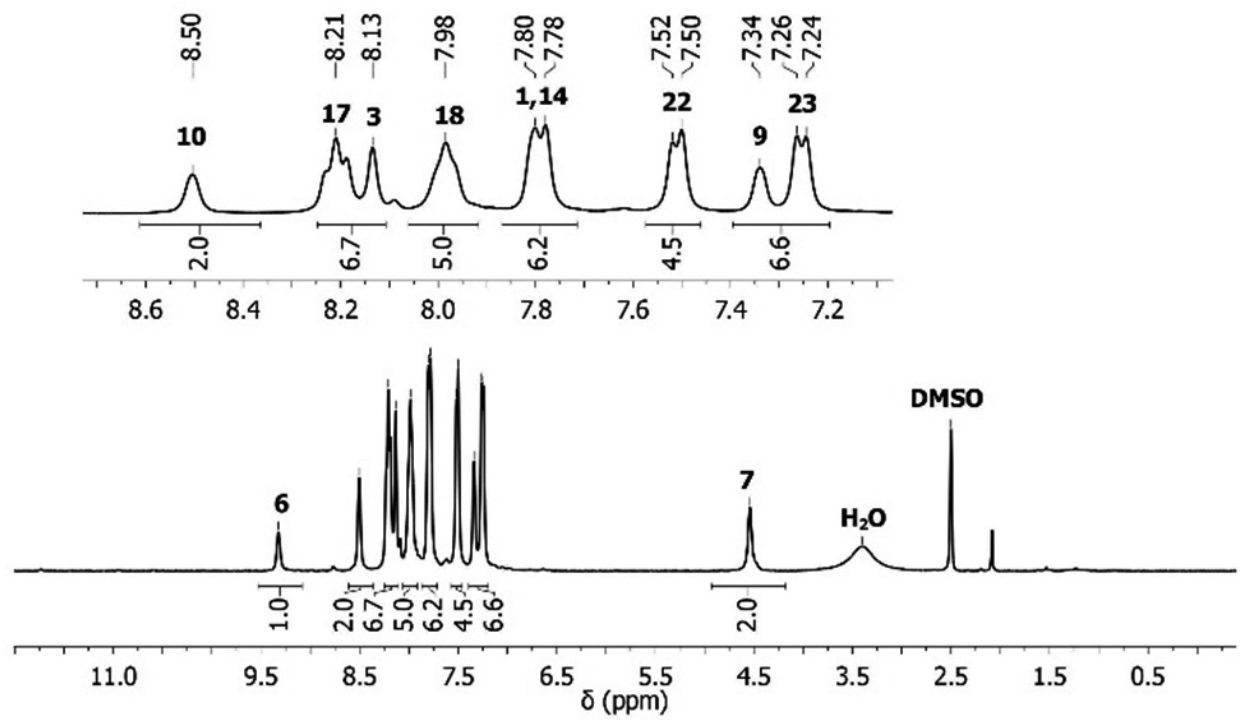

Figure 4 c: ๓ ర્ન

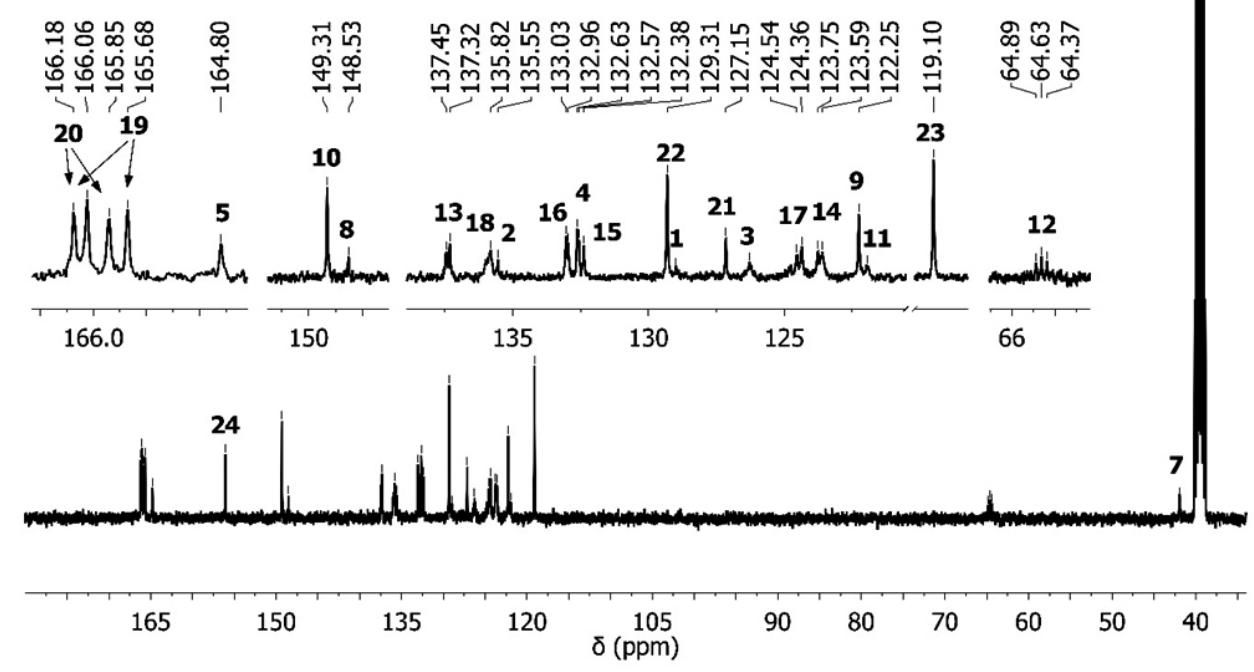

Figure 4. ${ }^{1} \mathrm{H}$ and ${ }^{13} \mathrm{C}$ NMR spectrum (400 MHz, DMSO- $d_{6}$ ) of PO6-5/5. 
Table 1. Inherent viscosity and solubility of PO6-Z/X.

\begin{tabular}{|c|c|c|c|c|c|c|c|}
\hline \multicolumn{2}{|c|}{$\mathbf{Z} / \mathbf{X}$} & $10 / 0$ & $7 / 3$ & $5 / 5$ & $3 / 7$ & 0/10 & $0 / 10^{c}$ \\
\hline \multicolumn{2}{|c|}{$\eta_{\text {inh }}(\mathbf{d L} / \mathbf{g})^{\mathbf{a}}$} & 0.30 & 0.33 & 0.57 & 0.53 & 1.49 & 1.42 \\
\hline \multirow{10}{*}{ 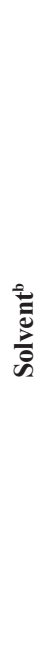 } & DMSO & + & + & + & + & + & + \\
\hline & DMA & + & + & + & + & + & + \\
\hline & DMF & + & + & + & + & $*$ & + \\
\hline & NMP & + & + & + & + & + & + \\
\hline & $\left(\mathrm{CH}_{3}\right)_{2} \mathrm{CO}$ & $*$ & * & $*$ & - & - & - \\
\hline & МеОН & $*$ & - & - & - & - & - \\
\hline & EtOH & $*$ & - & - & - & - & - \\
\hline & THF & $*$ & - & + & + & * & + \\
\hline & $\mathrm{CHCl}_{3}$ & $*$ & * & $*$ & $*$ & ++ & + \\
\hline & $\mathrm{Et}_{2} \mathrm{O}$ & - & - & - & - & - & - \\
\hline
\end{tabular}

a) $\mathrm{c}=50 \mathrm{mg}$ in $10 \mathrm{~mL}$ of $\mathrm{NMP}$, at $30^{\circ} \mathrm{C}$, b) $\mathrm{c}=10 \mathrm{mg}$ in $1 \mathrm{~mL}$ of solvent + soluble at $\mathrm{RT},++$ soluble at $40{ }^{\circ} \mathrm{C}$, - insoluble, $*$ swell. c) viscosity and solubility values described by Bong et al..$^{33}$

\subsection{Thermal properties}

Table 2 shows the degradation temperature values obtained from the TGA thermograms (Figure 5) and DTG analysis (Figure 6), together with the values of $\mathrm{TDT}_{10 \%}, \mathrm{Tg}$ and char yield obtained by Bong et al. for PO6-0/10. ${ }^{33}$ It is clear that as the pendant pyridinyl groups increase or decrease the different degradation temperatures are modifying for co-polymers.

Table 2 shows the degradation temperature values obtained from the TGA thermograms (Figure 5) and DTG analysis (Figure 6). It is clear that as the pendant pyridinyl groups increase or decrease the different degradation temperatures are modifying for co-polymers.

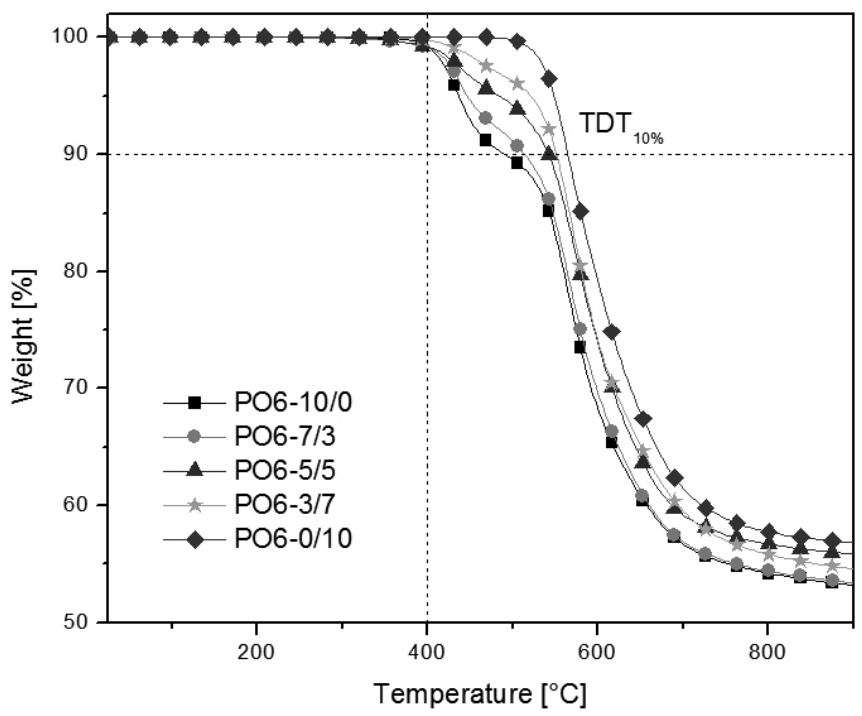

Figure 5. TGA thermograms of $\mathrm{PO6}-\mathrm{Z} / \mathrm{X}$ recovered under nitrogen atmosphere.

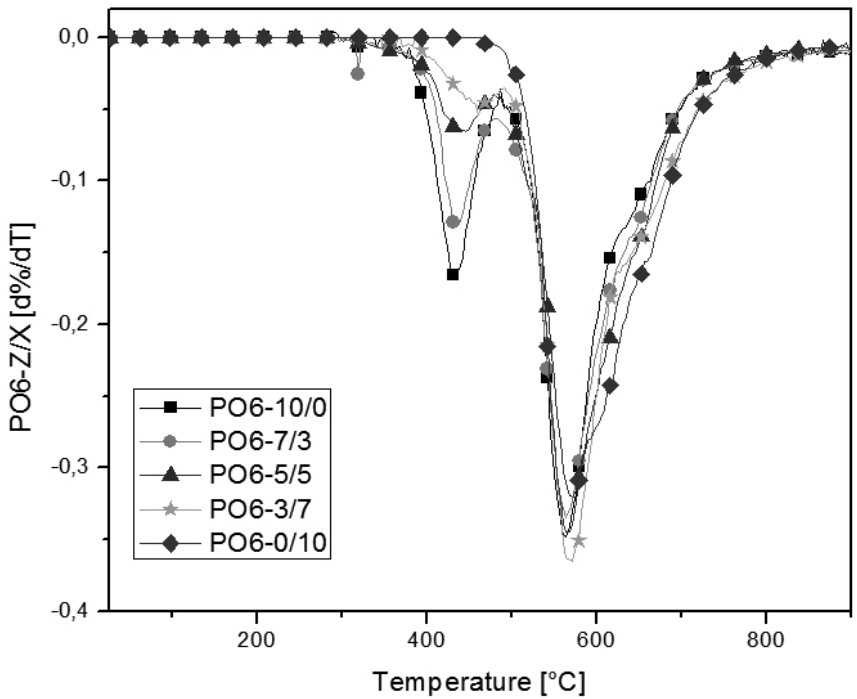

Figure 6. DTG curves of PO6-Z/X.

All polymers have a thermal decomposition (TDT ${ }_{10}^{\circ}$ ) above $480{ }^{\circ} \mathrm{C}$ and an onset of thermal degradation (OTD) over $370^{\circ} \mathrm{C}$. These values indicate that the synthesized polymers are thermally stable, which was expected due to the high content of aromatic rings and cyclic imide groups in the chains. Likewise, both the TDT ${ }_{10 \%}$ and the OTD decrease when the number of pyridinyl groups increases, which is attributed to the breakdown of the aliphatic portion that links this lateral moiety with the main chain. This fact is ratified by looking at the values of the maximum degradation temperature $\left(\mathrm{MDT}_{1}\right)$ showed in Table 2. MDT, shows the same trend as the OTD values, decomposition that only the polymers that contain the pyridinyl group show. In this sense, Table 3 shows the direct relationship between the decrease in the percentages of pyridinyl groups in the polymer chains and the decrease in the percentage of mass lost for the first thermal degradation.

Table 2. Summary of thermal properties of PO6-Z/X.

\begin{tabular}{|c|c|c|c|c|c|c|}
\hline $\mathbf{X} / \mathbf{Y}$ & $10 / 0$ & $7 / 3$ & $5 / 5$ & $3 / 7$ & $0 / 10$ & $0 / 10^{\mathrm{f}}$ \\
\hline TDT $_{10 \%}\left[{ }^{\circ} \mathrm{C}\right]^{\mathrm{a}}$ & 483 & 509 & 541 & 549 & 565 & 581 \\
\hline OTD $\left[{ }^{\circ} \mathbf{C}\right]^{b}$ & 390 & 374 & 378 & 416 & 509 & - \\
\hline $\operatorname{MDT}_{1}\left[{ }^{\circ} \mathbf{C}\right]^{\mathrm{c}}$ & 442 & 439 & 446 & 461 & - & - \\
\hline $\mathrm{MDT}_{2}\left[{ }^{\circ} \mathrm{C}\right]^{\mathrm{c}}$ & 564 & 564 & 572 & 572 & 564 & - \\
\hline Char yield [\%] ${ }^{d}$ & 53 & 53 & 56 & 55 & 57 & 57 \\
\hline $\operatorname{Tg}\left[{ }^{\circ} \mathrm{C}\right]^{\mathrm{e}}$ & 305 & 299 & 289 & 305 & 322 & 307 \\
\hline
\end{tabular}

a) Thermal decomposition at which $10 \%$ weight loss, b) Onset of therma degradation, c) Maximum degradation temperature, d) Residual weight when heated to $900{ }^{\circ} \mathrm{C}$, e) Glass transition temperature, f) $\mathrm{TDT}_{10 \%}, \mathrm{Tg}$ and char yield values described by Bong et al..$^{33}$

The second thermal degradation observed for the polymers, $\mathrm{MTD}_{2}$, in the range of 564 to $572{ }^{\circ} \mathrm{C}$, quite similar in degradation temperature, accounts for the rupture of the main chain, which is comprised mainly of aromatic rings and cyclic imide groups, the latter being the most prone to degradation.

The last line of Table 2 shows the Tg values for PO6 polymers, where they show two trends. The first is the increase of the values from PO6-5/5 to PO6-10/0, which is a consequence of increase in the density of imide groups, higher content of aromatic groups and the greater number of amide groups present. These originate attractive interactions such charge transfer complexes, $\pi$-stacking and the formation of hydrogen bonds. Figure 7 shows the interactions contributed by the portion derived from PyDA. The second trend is the increase in the Tg from PO6-5/5 to PO6-0/10, probably attributable to the greater degree of packaging that the chains produce due to the lower number of pyridinyl groups as shown by PO6-0/10 that has the highest Tg of all the polymers. 
Table 3. Lost mass and heavy pyridinyl group.

\begin{tabular}{|c|c|c|}
\hline PO6 & $\mathbf{L M}_{\mathbf{1}}(\mathbf{\%})^{\mathbf{a}}$ & PG (\%) $\mathbf{~}^{\mathbf{b}}$ \\
\hline $\mathbf{1 0} / \mathbf{0}$ & 9,0 & 14 \\
\hline $\mathbf{7 / 3}$ & 7,5 & 10 \\
\hline $\mathbf{5 / 5}$ & 4,4 & 7 \\
\hline $\mathbf{3} / \mathbf{7}$ & 2,9 & 4 \\
\hline $\mathbf{0 / 1 0}$ & 0 & 0 \\
\hline
\end{tabular}

a) Mass lost in the first thermal degradation.

b) Content of pyridinyl groups in the sample.

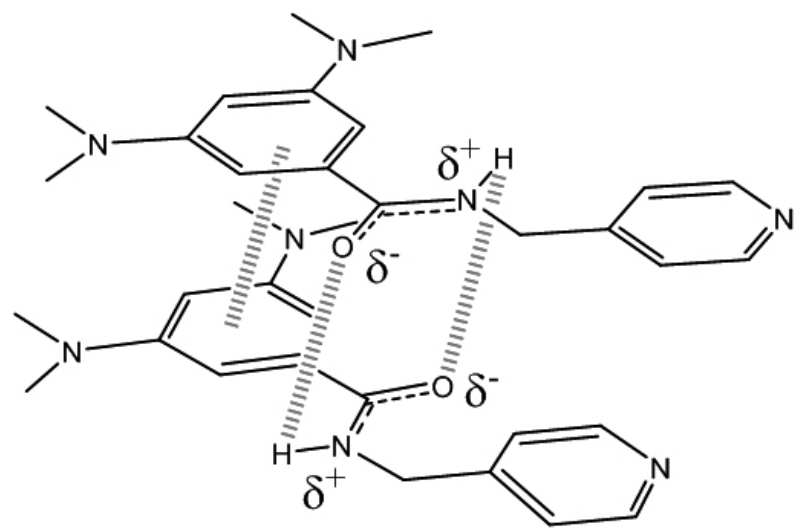

Figure 7. Description of $\pi$-stacking and hydrogen bonds between PyDA fragments

3.5 Mechanical properties and Wide-angle X-ray diffraction (WAXD)

Table 4 summarizes the values obtained from the tensile tests carried out on the films manufactured from the synthesized co-polymers, except for the PO6-10/0 film which was not able to maintain its shape for the analysis. In addition, the values of Young's module, tensile strength and elongation at break of PO6-0/10 obtained by Huang et al. are included as reference. ${ }^{34} \mathrm{Co}-$ polymers PO6-5/5 to PO6-0/10 show a greater resistance to deformation and rupture, as well as a greater elongation prior to rupture. The first result is due to the greater number of interactions resulting from the increase in the size of the chains, while the elongation of the co-polymers is favored by the greater number of ether units, which increase the flexibility of the chains. ${ }^{35}$

Table 4. Summary of mechanical properties of PO6-Z/X.

\begin{tabular}{|c|c|c|c|c|}
\hline Sample & $\begin{array}{c}\text { Young's } \\
\text { modulus } \\
\text { (Gpa) }\end{array}$ & $\begin{array}{c}\text { Yield } \\
\text { strength } \\
\text { (Mpa) }\end{array}$ & $\begin{array}{c}\text { Tensile } \\
\text { strength } \\
\text { (Mpa) }\end{array}$ & $\begin{array}{c}\text { Elongation } \\
\text { at break } \\
\text { (\%) }\end{array}$ \\
\hline PO6-7/3 & $3.9 \pm 1.1$ & $85.4 \pm 3.1$ & $120.4 \pm 2.4$ & $4.5 \pm 1.0$ \\
\hline PO6-5/5 & $2.1 \pm 0.9$ & $35.5 \pm 3.9$ & $35.5 \pm 3.9$ & $1.7 \pm 0.4$ \\
\hline PO6-3/7 & $2.2 \pm 0.3$ & $65.2 \pm 2.1$ & $88.8 \pm 3.6$ & $5.3 \pm 1.1$ \\
\hline PO6-0/10 & $2.5 \pm 0.2$ & $67.0 \pm 3.4$ & $75.2 \pm 4.3$ & $6.8 \pm 0.7$ \\
\hline PO6-0/10 & $1.5 \pm 0.0$ & - & $91.2 \pm 0.0$ & $15.3 \pm 0.0$ \\
\hline
\end{tabular}

a) Young's module, tensile strength and elongation at break values of PO6-0/10 obtained by Huang et al. ${ }^{34}$

The obtained values for PO6-7/3 indicate that this material is resistant to deformation. This would be associated to the capacity of $\pi$-stacking, hydrogen bonds and charge transfer interactions in comparison with the other copolymers, while PO6-5/5 shows a minimum value for all mechanical properties indicating a dilution of interactions and a possible formation of two separated phases. Lower concentrations of pyridinyl groups increases yield strength, tensile strength and deformation ability since they are rich in the ODA diamine which dilutes further the pyridinyl interactions and imparts some flexibility due to the presence of the ether group. Figure 8 shows the diffractograms of the co-polymers where the amorphous halo observed for all co-polymers with a maximum at 17 degrees $2 \theta$ indicates that they do not crystallize. This value is associated to an average distance, $\mathrm{d}$-spacing, value between neighboring chains using Bragg's equation $(\mathrm{d}=\mathrm{n} \lambda / 2 \sin \theta)$. In this particular case $\mathrm{l}=1.54 \mathrm{~A}$ and $\mathrm{d}$ $=5.2 \mathrm{~A}$ represents the average distance between polymer chains.

Then, from the diffractograms it can be concluded that from PO6-5/5 to PO6-0/10 the polymers have similar $\mathrm{d}$-spacing and that this parameter is not affected by the PyDA amount.

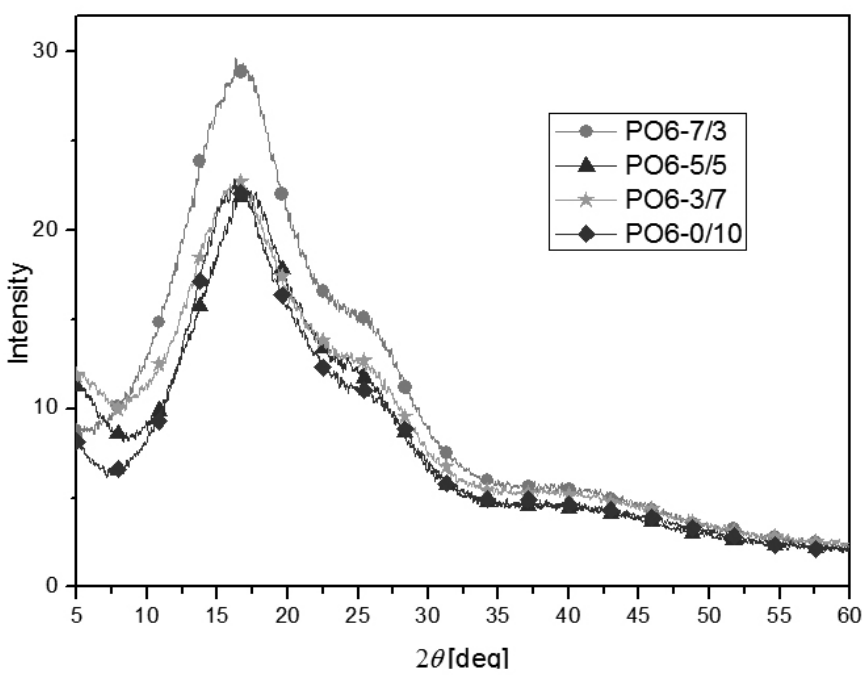

Figure 8. Diffractograms of PO6-X/Z polymers

3.6 Surface properties

In order to study the behaviour of the surface of the samples, analyses on PO6-10/0, PO6-5/5 and PO6-0/10 were carried out.

3.6.1 Contact angle and surface energy

Table 5 shows the contact angle determination results in the polymers and the calculations of surface energy (SE) based on the Owens-Wendt-RabelKaelble method, ${ }^{36-38}$ using water and methanol as a solvent. The latter was used because solvents such as $n$-heptane and toluene were not able to form stable drops on the surface of the films, product of the strong interaction between the samples and them.

Table 5. Contact angle and surface energy.

\begin{tabular}{|c|c|c|c|c|c|}
\hline \multicolumn{2}{|c|}{ PO6- } & $\boldsymbol{\theta}_{\mathbf{Y}}\left(^{\circ}\right)^{\mathbf{a}}$ & SE $^{\mathbf{b}}$ & Dispersion $^{\mathbf{b}}$ & Polar $^{\mathbf{b}}$ \\
\hline \multirow{2}{*}{$\mathbf{1 0 / 0}$} & $\mathbf{H}_{\mathbf{2}} \mathbf{O}$ & $106.3 \pm 2.7$ & \multirow{2}{*}{15.7} & 14.0 & 1.6 \\
\cline { 2 - 4 } & $\mathbf{M e O H}$ & $54.8 \pm 0.7$ & & & \\
\hline \multirow{2}{*}{$\mathbf{5} / \mathbf{5}$} & $\mathbf{H}_{\mathbf{2}} \mathbf{O}$ & $108.6 \pm 2.5$ & \multirow{2}{*}{22.4} & 22.1 & 0.2 \\
\cline { 2 - 4 } & $\mathbf{M e O H}$ & $48.8 \pm 0.8$ & & & \\
\hline \multirow{2}{*}{$\mathbf{0} / \mathbf{1 0}$} & $\mathbf{H}_{\mathbf{2}} \mathbf{O}$ & $108.7 \pm 0.1$ & \multirow{2}{*}{25.8} & 25.7 & 0.1 \\
\cline { 2 - 4 } & $\mathbf{M e O H}$ & $42.9 \pm 1.9$ & & & \\
\hline
\end{tabular}

a Contact angle recorded at rate of $10 \mu \mathrm{L} / \mathrm{s}$ at $25^{\circ} \mathrm{C}$, b Surface energy and its components in $\mathrm{m} N / \mathrm{m}$.

The contact angles recorded for water show that all tested samples have a hydrophobic surface with values greater than $90^{\circ}$ (Figure 9). This is due to the scarce presence of polarized bonds such as $\mathrm{O}-\mathrm{H}$ or $\mathrm{N}-\mathrm{H}$, which would form hydrogen bonds with water and also to the greater amount of dispersion forces contributed by the high aromatic content. The comparison of the values of surface energy and its components obtained for the water-surface systems, show that a higher content of pyridinyl groups along the chain increases the hydrophilic character of the surfaces, which is attributed to the hydrogen-bond type interactions contributed by the amide and pyridinyl groups. 
a)

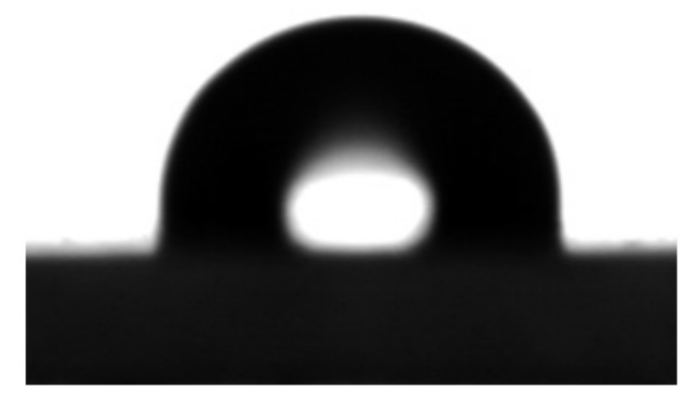

b)

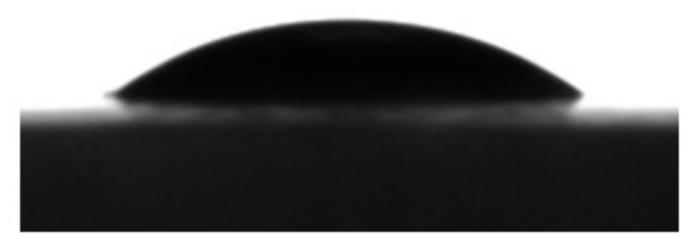

Figure 9. Example of droplet profiles on polymers. a) Water on PO6-5/5, b) Methanol on PO6-5/5

3.6.2 AFM and FE-SEM microscopy

To know the surface morphology, FE-SEM and AFM microscopy was performed. Images obtained in these analyses are shown in figures 10 and 11 respectively. In Figure 10, it is seen that all samples form uniform films,

a)

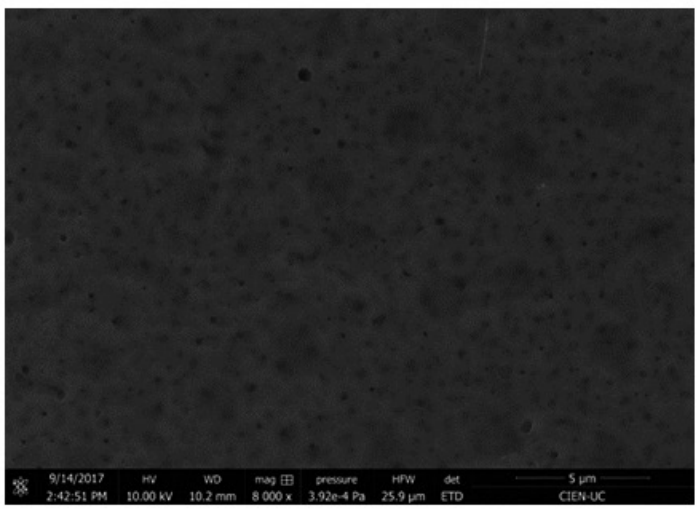

that are typical of the manufacturing process used and the usual behaviour for these type of polymers. ${ }^{39-41}$ Furthermore, it is possible to see small cavities on the surface of the films due to the formation of solvent droplets during the evaporation process. ${ }^{42}$

b)

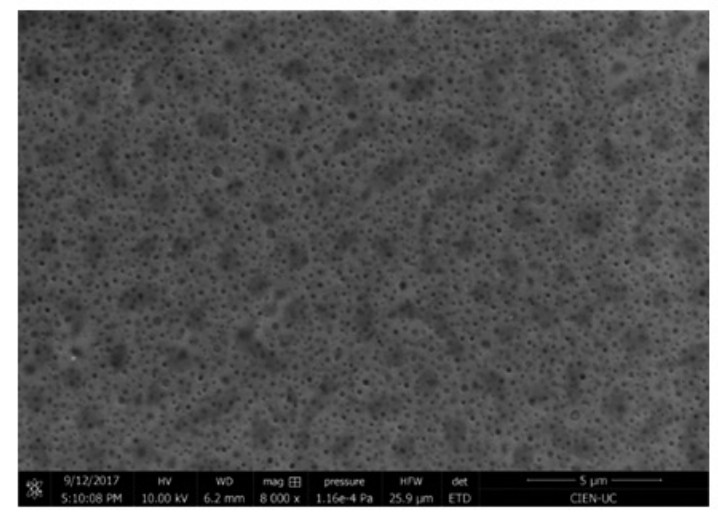

c)

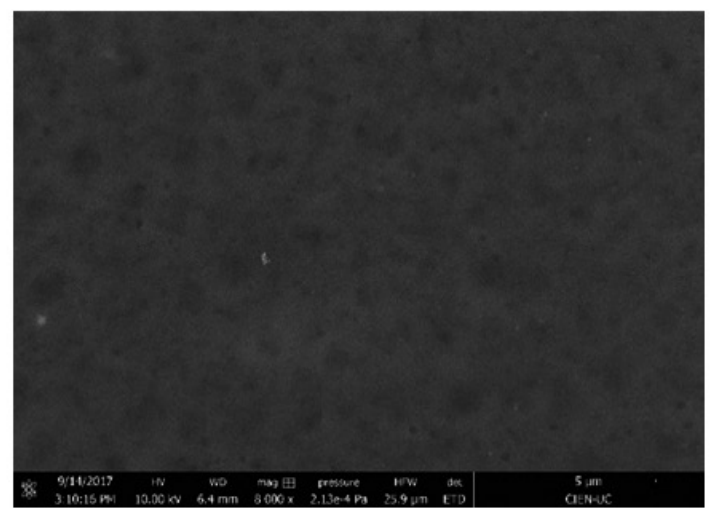

Figure 13. FE-SEM images obtained at $5 \mu \mathrm{m}$, supported by silicon wafer. a) PO6-10/0, b) PO6,-5/5 c) PO6-0/10

The observed behaviour by FE-SEM is confirmed by the profiles obtained from AFM analysis (Figure 11) where the resulting images for the topography of PO6-5/5 is shown as an example. These images ensure that the films formed will be able to offer uniform contact surfaces and little rough 


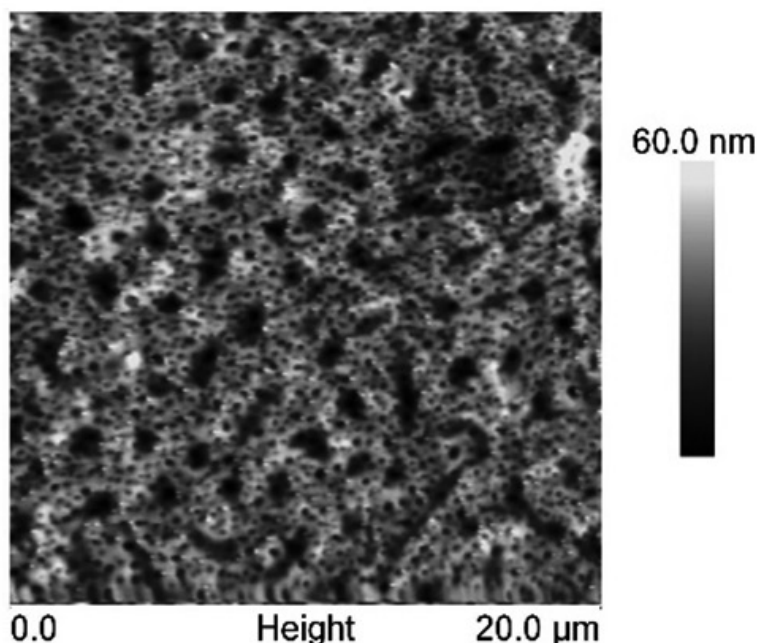

Figure 14. 2D and 3D images of the surface of PO6-5/5 obtained by AFM

\section{CONCLUSIONS}

A set of co-polyimides derived from the 6FDA dianhydride having varying amounts of ODA and PyDA diamines were synthesized and characterized. The new materials showed a dependence of their specific properties on the proportion of ODA and PyDA used in the synthesis process. Among which stand out a decrease in the temperature of decomposition without affecting its high thermal stability, a slight increase in hydrophilicity and interactions with protic polar solvent product of the increase in the fragments derived from PyDA. There is also an improvement in mechanical performance and viscosity as a result of the increase in fragments derived from ODA.

In addition, all polymers showed to be amorphous, soluble in common aprotic polar solvents and generate dense and uniform films.

\section{AGRADECIMIENTOS ACKNOWLEDGMENT(S)}

In memory to the Dr. José Luis Santiago-Garcia, Rest in peace.

Ortiz, P. acknowledges the financial assistance by Comisión Nacional de Investigación Científica y Tecnológica, CONICYT, through FONDECYT/ POSTDOCTORADO/project 3160440, Fondequip project EQM150101 for the images of FE-SEM microscopy and PROJECT EQM120021 for the NMR analysis.

\section{REFERENCES}

1. C.E. Sroog, J. Polymer Sci. Macromol. Rev., 11, 161 (1976).

2. J. García, F. García, F. Serna y J. de la Peña, Prog Polym Sci, 35, 623, (2010)

3. A.S. Dhindsa, Y.P. Song, J.P. Badyal, M.R. Bryce, Y.M. L'Vov, M.C. Petty, J. Yarwood, Chem. Mater., 4, 724 (1992).

4. K. Takatoh, M. Hasegawa, M. Koden, N. Itoh, R. Hasegawa, M. Sakamoto. Alignment technologies and applications of liquid crystal devices. London, U.K.; Taylor \& Francis; 2005. p. 59-63.

5. D. Guzmán-Lucero, J. F. Palomeque-Santiago, C. Camacho-Zuñiga, F. Ruiz-Traviño, J. Guzmán, A. Galicia-Aguilar, C. Aguilar-Lugo, Mater., 8, 1951 (2015).

6. O.J. Dautel, G. Wantz, D. Flot, J.P. Lere-Porte, J.J.E. Moreau, J.P. Parneix, F. Serein-Spirau, L. Vignau, J. Mater. Chem., 15, 4446 (2005)

7. Y. Kim, J.G. Lee, K. Han, H.K. Hwang, D.K. Choi, Y.Y. Jun, J.H. Keum, S. Kim, S.S. Park, W.B. Im, Thin Solid Films, 363, 263 (2000).

8. B. Smitha, S. Sridhar, A.A. Khan, J. Membra. Sci., 259, 10 (2000).

9. J. Fang, X. Guo, S. Harada, T. Watari, K. Tanaka, H. Kita, K.I. Okamoto, Macromol., 35, 9022 (2002)

10. M. Shigeta, M. Komatsu, N. Nakashima, Chem. Phys. Lett., 418, 115 (2006)

11. K.L. Wang, Y.L. Liu, J.W., Lee, K.G. Neoh, Macromol., 43, 7159 (2010).

12. J. A. Reglero, M. Trigo-López, F.C. García, J. M. García, Polymers, 9, 414 (2017).

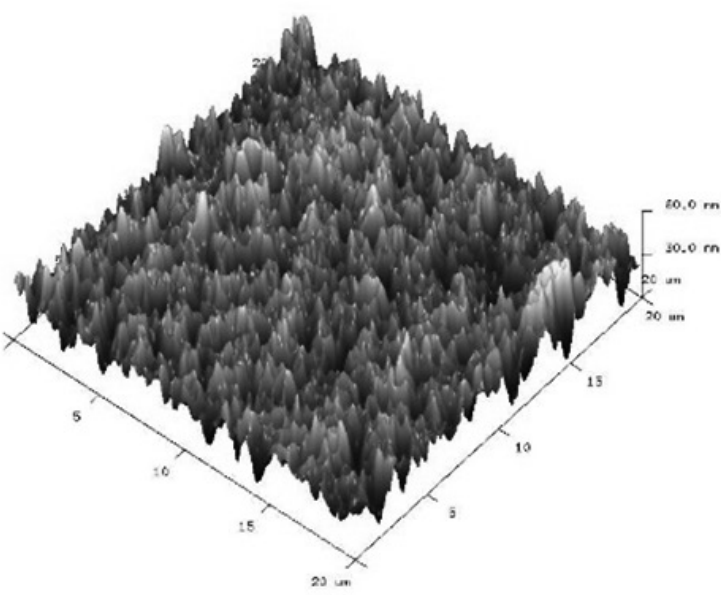

13. J.M. Gohil, P. Ray, Sep Purif Technol, 181, 159 (2017).

14. M. Kim, M. Kim, B. Park, S. Kim, Desalin Water Treat, 54, 923 (2015)

15. B.V. Kotov, T.A. Gordina, V.S. Voishchev, O.V. Kolninov, A.N Pravednikov, Polym. Sci. U.S.S.R., 9, 711 (1977)

16. F. Ke, N. Song, D. Liang, H. Xu, J. Appl. Polym. Sci., 127, 797 (2013).

17. M. G. Dhara, S. Banerjee, Prog. Polym. Sci., 35, 1022 (2010).

18. D.J. Liaw, B.Y. Liaw, C.W. Yu, Polymers, 42, 5175 (2001).

19. K. Xie, J.G. Liu, H.W. Zhou, S.Y. Zhang, M.H. He, S.Y. Yang, Polymers, 42, 7267 (2001)

20. C.L. Chung, W.F. Lee, C.H. Lin, S.H. Hsiao, J. Polym. Sci.: Part A Polym. Chem., 47, 1756 (2009)

21. J. M. García, F.C. García, F. Serna, J. Polym. Sci.: Part A: Polym. Chem., 41, 1202 (2003).

22. C.P. Yang, R.S. Chen, K.S. Hung, Polymers, 42, 4569 (2001).

23. J. Yao, C. Wang, C. Tian, X. Zhao, H. Zhou, D. Wang, C. Chen, Des. Monomers Polym., 20, 449 (2017).

24. J. Zang, Z. Zhu, H. Sun, W. Liang, A. L, React. Funct. Polym., 99, 95 (2016)

25. S. Zhang, X. Li, X. Guan, Y. Shi, K. Wu, L. Liang, J. Shi, M. Lu, Compos. Sci. Technol., 152, 165 (2017).

26. J. Yao, C. Wang, X. Zhao, H. Zhou, C. Chen, D. Wang, High Perform. Polym., 30, 418 (2018)

27. D. Liaw, K. Wang, F. Chang, Macromol., 40, 3568 (2007).

28. Z. Yang, H. Wang, G. Ji, X. Yu, Yu Chen, X. Liu, C. Wua, Z. Liu, New J. Chem., 41, 2869 (2017).

29. L.C. Lee, J. He, J.Q. Yu, C.W. Jones, ACS Catal., 6, 5245 (2016).

30. H. Cui, Y. Chen, L. Li, Y. Wu, Z. Tang, H. Fu, Z. Tian, Microchim. Acta, $181,1529(2014)$

31. S. Pereira, A. Barros-Timmons, T. Trindade, Polymers, 10, 189 (2018)

32. A. Arizaga, G. Ibarz, R. Piñol, A. Urtizberea, J. Exp. Nanosci., 9, 561 (2014)

33. S. Bong, H. Yeo, B. Ku, M. Goh, N. You, Macromol Res, 26, 85 (2018).

34. Z. Huang, J. Zhao, RSC Adv, 6, 34825 (2016).

35. M. Barikani, S. Mehdipour-Ataei, J. Polym. Sci.: Part A: Polym. Chem., 38, 1487 (2000)

36. Owens, D.K.; Wendt, R.C., J. Appl. Polym. Sci., 13, 1741 (1969).

37. D. H. Kaelble, J. Adhes., 2, 66 (1970).

39. J. Park, L. Drahushuk, M. Ham, S. Kang, J. Baik, S. Shimizu, M. S. Strano, C. Song, Polym Chem, 4, 290 (2013).

38. N. Encinas, M. Pantoja, J. Abenojar, M. A. Martínez, J. Adhes. Sci Technol., 24, 1869 (2010).

40. T.G. Woo, I.S. Park, K.H. Jung, W.Y. Jeon, K.W. Seo, Met. Mater. Int., 17, 789 (2011)

41. C. R. Gautreaux, J. R. Pratt, T.L. St. Clair, J. Polym. Sci.: Part B: Polym Phys., 30, 71 (1992).

42. Y. Wang, Z. Liu, B. Han, Z. Sun, J. Zhang, D. Sun, Adv. Funct. Mater., 15, 655 (2005) 